\title{
Differential physiological response of the grapevine varieties Touriga Nacional and Trincadeira to combined heat, drought and light stresses
}

\author{
L. C. Carvalho ${ }^{1}$, J. L. Coito ${ }^{1}$, E. F. Gonçalves ${ }^{2}$, M. M. Chaves ${ }^{3}$ \& S. Amâncio ${ }^{1}$ \\ 1 DRAT, LEAF, ISA, Universidade de Lisboa, Lisboa, Portugal \\ 2 DCEB, LEAF, ISA, Universidade de Lisboa, Lisboa, Portugal \\ 3 Instituto de Tecnologia Química e Biológica, Universidade Nova de Lisboa, Oeiras, Portugal
}

\section{Keywords}

Abiotic stress; abscisic acid; ascorbateglutathione cycle; chlorophyll fluorescence; grapevine; photosynthesis; ROS.

\section{Correspondence \\ S. Amâncio, DRAT, LEAF, ISA, Universidade de Lisboa, Tapada da Ajuda, 1349-017 Lisboa, Portugal. \\ E-mail: samport@isa.ulisboa.pt}

\section{Editor}

L. J. De Kok

Received: 4 August 2015; Accepted: 19 October 2015

doi:10.1111/plb.12410

\begin{abstract}
Worldwide, extensive agricultural losses are attributed to drought, often in combination with heat in Mediterranean climate regions, where grapevine traditionally grows. The available scenarios for climate change suggest increases in aridity in these regions. Under natural conditions plants are affected by a combination of stresses, triggering synergistic or antagonistic physiological, metabolic or transcriptomic responses unique to the combination. However the study of such stresses in a controlled environment can elucidate important mechanisms by allowing the separation of the effects of individual stresses. To gather those effects, cuttings of two grapevine varieties, Touriga Nacional (TN) and Trincadeira (TR), were grown under controlled conditions and subjected to three abiotic stresses (drought - WS, heat - HS and high light - LS) individually and in combination two-by-two (WSHS, WSLS, HSLS) or all three (WSHSLS). Photosynthesis, water status, contents of $\mathrm{H}_{2} \mathrm{O}_{2}$, abscisic acid and metabolites of the ascorbate-glutathione cycle were measured in the leaves. Common and distinct response features were identified in the different stress combinations. Photosynthesis was not hindered in TN by LS, while even individual stresses severely affect photosynthesis in TR. Abscisic acid may be implicated in grapevine osmotic responses since it is correlated with tolerance parameters, especially in combined stresses involving drought. Overall, the responses to drought-including treatments were clearly distinct to those without drought. From the specific behaviours of the varieties, it can be concluded that $\mathrm{TN}$ shows a higher capacity for heat dissipation and for withstanding high light intensities, indicating better adjustment to warm conditions, provided that water supply is plentiful.
\end{abstract}

\section{INTRODUCTION}

During their life cycle plants face a wide variety of environmental changes and, in time, have evolved mechanisms that enable them to tolerate extreme variations. These mechanisms include interactive cellular and molecular variations that start as soon as seconds after the onset of stress conditions. After perception of the stress signal and transmission of its information through a transduction pathway, modifications in gene expression, adjustment of cellular and molecular processes and responses at the physiological level occur (Knight \& Knight 2001).

Common abiotic stresses unfavourable to plant growth and crop yield include drought, salinity, extreme temperatures, acid soils and chemical pollution (Vinocur \& Altman 2005). Drought, salinity and chemical pollution can cause the same cellular damage, such as the accumulation of stress-related proteins, antioxidant metabolites and compatible solutes (Wang et al. 2003). It is commonly reported that primary stresses lead to secondary stresses, such as osmotic and oxidative stress (Wang et al. 2003). Oxidative stress is often a result of combinations of high temperature and drought, leading to denaturation of functional and structural proteins (Mittler
2006). Temperatures above the optimum are identified by living organisms as heat stress (HS) and can disrupt cellular homeostasis and lead to severe growth and development delay, and ultimately death (Kotak et al. 2007).

Plants growing under natural conditions are usually affected by interacting factors instead of just a single abiotic stress (Mittler 2006). Different stresses, when combined, can induce synergistic or antagonistic responses. An example is given in Rizhsky et al. (2002), who verified that heat stress combined with drought caused an opposite stomatal reaction as compared to heat stress alone. The same is true for salinity when combined with heat, because the higher transpiration rates caused by heat could lead to increased salt uptake (Wang et al. 2003). Also drought combined with high light can result in higher reactive oxygen species (ROS) production in the photosynthetic apparatus (Mullineaux et al. 2006).

When photoprotective mechanisms in leaves are not sufficient to protect the photosynthetic machinery, photoinhibition takes place and is traceable through the production of ROS (Mittler et al. 2004). However, a limited and tightly controlled amount of ROS act as signalling molecules (Mullineaux et al. 2006) and are often integrated into signalling pathways, such as 
the acclimation of plants grown under low light to high light (Mittler et al. 2004; Kwak et al. 2006; Mullineaux et al. 2006). ABA (abscisic acid) is known to regulate plant response to water and osmotic stress (Seki et al. 2007), operating at the whole plant level and regulating processes such as transpiration and water loss through stomatal closure. In cases where the balance between water uptake and water loss cannot be adjusted by primary adaptive responses, different mechanisms are triggered to avoid and/or tolerate dehydration, which involve regulation of the stress response through ABA and other signalling pathways (Zhu 2002). In particular, the regulated synthesis of dehydrins and LEA (late embryogenesis abundant) proteins and the accumulation of osmocompatible solutes are key factors in both retaining water and protecting proteins and membranes (Ingram \& Bartels 1996; Verslues et al. 2006). ABA also regulates protein synthesis, transport of ions and of organic molecules and the production of important protectants against dehydration and photoinhibition (Yang et al. 2006; Seki et al. 2007). GSH (reduced glutathione) plays a crucial role in the removal of ROS, namely hydrogen peroxide $\left(\mathrm{H}_{2} \mathrm{O}_{2}\right)$, produced under several abiotic stresses, especially cold, heat, drought and salt (Kranner et al. 2002; Kocsy et al. 2004; Mittova et al. 2004; Szalai et al. 2009). The changes in the size, redox state and compartmentalisation of the GSH pool are crucial at the cellular level (Noctor et al. 2013). In fact they are thought to be more important for the response to abiotic stress than the alteration of these parameters in various organs and tissues (Meyer 2008). Furthermore, the GSH pool is closely related to ABA since GSH content, GSH reduction ratio and glutathionemediated redox signalling are described as differentially affected by ABA (Pastori \& Foyer 2002; Kellos et al. 2008).

Worldwide, extensive agricultural losses are attributed to heat, often in combination with drought (Knight \& Knight 2001), namely in areas with a Mediterranean climate, the traditional growing region for grapevine. Furthermore, the available scenarios for climate change suggest an increase in aridity for the Mediterranean region in the near future, with a higher occurrence of extreme heat and/or drought episodes. This will lead to an over-exploitation of water resources for agriculture use, increasing limitations to plant growth and survival and therefore to fulfilling the potential crop yields (Chaves 2002; Chaves et al. 2003). In fact, by the late 21 st century, many European plant species, including grapevine, will have shifted their distribution several hundred kilometres northward and uphill. Plant phenology is also changing, with the timing of flowering and grape ripening occurring several days earlier than in previous years (Morison \& Morecroft 2006). This will necessarily lead to adjustments in viticulture; as perennial species are slow to adapt, we need to focus on the already existing variability in order to grow varieties that are more resilient to the upcoming changes.

Semi-arid regions where grapes are grown not only suffer from water deficit but also are prone to excess heat and light that often interact with water deficit, accelerating water loss and leading to stress. Nevertheless, a mild water deficit may have a positive impact on berry composition, resulting in smaller berries with enhanced sugars, flavours and colour, and therefore, increased quality (Castellarin et al. 2007; Deluc et al. 2009). A sound knowledge of the mechanisms that enable grapevine to deal with drought, high light and co-occurring temperature increase can play a key role in stabilising or even improving crop performance in those extreme conditions. Adequate management methodologies, among them irrigation, are tools to improve resource use efficiency of plants (Chaves et al. 2010).

The effects of abiotic stress on plant growth and functioning are mostly focused on individual stresses, although plant responses to a combination of stresses can hardly be extrapolated from the response to each of the individual stresses (Mittler 2006). Whether the monitored plants are growing in the field or in controlled conditions can also influence the response to environmental conditions, even altering phenotypic characteristics (Mishra et al. 2012). Although trials under natural conditions are needed to fully comprehend the whole picture of 'stress resistance' mechanisms in the field, the study of such stresses in a controlled environment can elucidate important mechanisms of resistance by allowing the separation of the effects of individual stresses.

In the present work we performed an experiment where we applied individual water (WS), heat (HS) and light (LS) stress and all the combinations between them to plants from cuttings of Touriga Nacional (TN) and Trincadeira (TR), two widely used wine-growing varieties, described as exhibiting distinct behaviours when faced with stress in the field. The results described in Costa et al. (2012) suggest that TN has a higher capacity for heat dissipation via evaporative cooling than TR, thus better adapted to withstand heat when water is plentiful. The cuttings used in the present study were analysed for photosynthetic performance through chlorophyll fluorescence and photosynthesis parameters, stomatal conductance, water potential, $\mathrm{H}_{2} \mathrm{O}_{2}$, pigments, $\mathrm{ABA}, \mathrm{GSH}$ and ascorbic acid (AsA) and their respective redox status. The main aim was to further understand the mechanisms of response and the antagonistic or synergistic effects that the combination of abiotic stresses can induce, and thus change the prior perceptions of 'tolerance' or 'sensitivity' of each variety. To achieve this, correlations between the parameters measured after individual and combined abiotic stresses were performed, and the physiologically significant ones are shown. The applied experimental set up allowed us to verify that TN and TR make specific adjustments to the stressful conditions. The assembled knowledge takes advantage of the varieties' plasticity of response when facing adverse conditions and can help to gather data on the adaptation of these varieties. A cautious extrapolation of the results obtained herein to field conditions could assist vine growers to choose the more adjusted varieties and viticultural practices to use when dealing with impending climate changes.

\section{MATERIAL AND METHODS}

\section{Plant material}

Pruned wood of selected plants of the varieties Touriga Nacional (TN) and Trincadeira (TR) was collected from a vineyard in Pegões (Peninsula de Setúbal, Portugal) and cuttings with five buds were prepared, treated with fungicide (Benlate, $2 \%$ ), kept at $4{ }^{\circ} \mathrm{C}$ for 2 months, and then treated again with fungicide. The cuttings were then rooted in distilled water with complete nutrient solution (10:1, v:v; Rhue et al. 1978) in darkened vessels. After rooting they were placed in 3-1 pots filled with sterilised soil, well watered with nutrient solution whenever necessary, in a walk-in growth room under controlled condi- 
tions with irradiance of $300 \mu \mathrm{mol} \cdot$ quanta $\cdot \mathrm{m}^{-2} \cdot \mathrm{s}^{-1}$, photoperiod of 16-h light/8-h dark provided by fluorescent lamps (Gro-Lux F18W/GRO) and temperature of $25^{\circ} \mathrm{C}$ day/23 ${ }^{\circ} \mathrm{C}$ night.

\section{Experimental setup/Stress treatments}

Individual stresses were applied in a climate-controlled room when circa 4-month-old plants were $70-\mathrm{cm}$ high. Out of a total of 100 plants per variety, 48 were chosen for the treatments (six for each of the seven stress treatments and six more for the control) in a randomised complete design, with six replicates. The stresses applied were: light stress (LS), $1 \mathrm{~h}$ at $2000 \mu \mathrm{mol} \cdot$ quanta $\cdot \mathrm{m}^{-2} \cdot \mathrm{s}^{-1}$ provided by and optical fibre and LEDs in order to avoid secondary heat effects; heat stress (HS), $1 \mathrm{~h}$ at $42{ }^{\circ} \mathrm{C}$ (temperature measured at the surface of the leaf) provided by a homogenous heat source; water deficit stress (WS), measurements as soon as pre-dawn leaf water potential $\left(\Psi_{\mathrm{w}}\right)$ reached $-0.9 \mathrm{MPa}$ a value that is consistent with a severe water stress (Chaves 2002) obtained after 4 days without irrigation for TR and 5 days for TR. $\Psi_{\mathrm{w}}$ was measured with a pressure chamber, Model 600 (PMS Instruments, Albany, OR, USA).

The combined stress treatments correspond to the application of two or three of the above-mentioned individual stresses. Thus, the following combined stresses were applied (Fig. 1): WSLS, corresponding to $1 \mathrm{~h}$ at $2000 \mu \mathrm{mol} \cdot$ quanta $\cdot \mathrm{m}^{-2} \cdot \mathrm{s}^{-1}$ and at $42{ }^{\circ} \mathrm{C}$; WSHS, $1 \mathrm{~h}$ at $42^{\circ} \mathrm{C}$ applied when $\Psi_{\mathrm{w}}$ reached

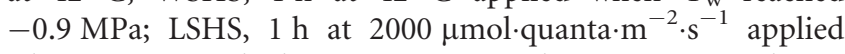
when $\Psi_{\mathrm{w}}$ reached $-0.9 \mathrm{MPa}$; and WSLSHS, $1 \mathrm{~h}$ at $2000 \mu \mathrm{mol} \cdot$ quanta $\cdot \mathrm{m}^{-2} \cdot \mathrm{s}^{-1}$ and at $42{ }^{\circ} \mathrm{C}$ applied when $\Psi_{\mathrm{w}}$ reached $-0.9 \mathrm{MPa}$.

Immediately at the end of each treatment leaf samples were taken for $\mathrm{H}_{2} \mathrm{O}_{2}$, chlorophylls, carotenoids, abscisic acid, reduced and oxidised ascorbate and glutathione quantification.

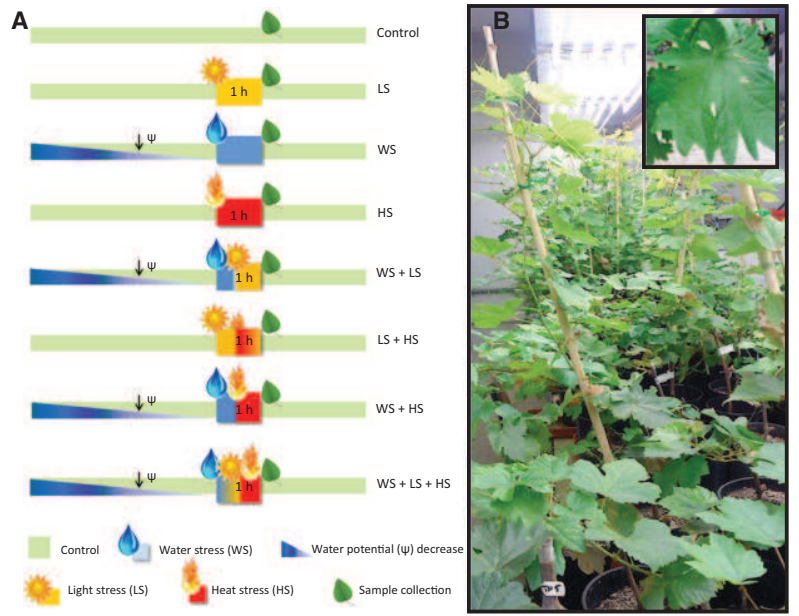

Fig. 1. (A) Experimental design for applying individual and combined water deficit, light and heat stress to two grapevine varieties, Touriga Nacional (TN) and Trincadeira (TR), and (B) overall aspect of the experimental plants and a close-up of a leaf. Plants were subjected to the stresses as described in 'Material and methods'. This design attempts to simulate conditions that might occur in the field in which a relatively prolonged period of water deficit (blue) is accompanied by a brief period of heat stress (red) and/or high light intensity (yellow).
Photosynthetic performance was assessed through light curves that began at the end of the stress treatments and took circa $30 \mathrm{~min}$ to complete, and during this period the plants were subjected to the stress conditions of each respective treatment. Six biological replicates were performed for photosynthesis and chlorophyll fluorescence and five biological replicates were used for all the other quantifications, in each experimental condition (individual and combined stresses).

\section{Quantification of $\mathrm{H}_{2} \mathrm{O}_{2}$}

Production of $\mathrm{H}_{2} \mathrm{O}_{2}$ was detected using a fluorometric horseradish peroxidase (HRP) linked assay (Amplex Red assay kit; Invitrogen, Carlsbad, CA, USA). Leaf material (0.1 g) was collected at each time point and ground over activated charcoal in the presence of liquid $\mathrm{N}_{2}$ as described in Creissen et al. (1999). Samples were centrifuged for $10 \mathrm{~min}$ at maximum speed and the supernatants were kept on ice until measurements. $\mathrm{H}_{2} \mathrm{O}_{2}$ concentrations in purified extracts were determined according to the manufacturer's instructions. Absorbance was then measured with a microplate reader at $570 \mathrm{~nm} . \mathrm{H}_{2} \mathrm{O}_{2}$ concentrations were expressed in $\mu \mathrm{mol} \cdot \mathrm{g}^{-1}$ dry weight (DW).

\section{Pigment quantification}

Chlorophyll, carotenoids and anthocyanins were extracted from four leaf disks (total area $113 \mathrm{~mm}^{2}$ ). Disks were incu-

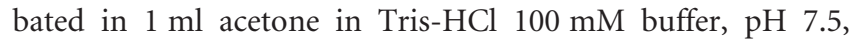
(80:20) and centrifuged at $12,000 \mathrm{~g}$ for $15 \mathrm{~min}$. The supernatants were used for quantification. Absorbance was measured at 537, 647 and $663 \mathrm{~nm}$ for chlorophylls and anthocyanins and at $470 \mathrm{~nm}$ for carotenoids. Pigment concentrations were calculated using the equations described in Sims \& Gamon (2002): Chla $\left(\mu \mathrm{mol} \cdot \mathrm{ml}^{-1}\right)=0.01373 \times A 663-0.000897 \times A_{537}-$ $0.003046 \times A_{647} ; \quad$ Chl $b \quad\left(\mu \mathrm{mol} \cdot \mathrm{ml}^{-1}\right)=0.02405 \times A_{647} \quad-$ $0.004305 \times A_{537}-0.005507 \times A_{663} ;$ tot $\mathrm{Chl}\left(\mu \mathrm{mol} \cdot \mathrm{ml}^{-1}\right)=$ Chl $a+$ Chl $b$, carotenoids $\left(\mu \mathrm{mol} \cdot \mathrm{ml}^{-1}\right)=\left(\mathrm{A}_{470}-17.1 \times\right.$ totChl $-9.479 \times$ anthocyanins $) / 119.26$; anthocyanins $\left(\mu \mathrm{mol} \cdot \mathrm{ml}^{-1}\right)=$ $0.08173 \times A_{537}-0.00697 \times A_{647}-0.002228 \times A_{663}$. Values were converted to $\mathrm{mg} \cdot \mathrm{cm}^{-2}$ leaf area (Richardson et al. 2002).

\section{Photosynthesis and chlorophyll fluorescence measurements}

Photosynthetic rate at ambient $\mathrm{CO}_{2}$ and light response curves were measured immediately after the end of the 1-h stress or, in the case of WS, when $\Psi_{\mathrm{w}}$ was $-0.9 \mathrm{MPa}$, on the third fully expanded leaf of each plant, using an open gas exchange system (LI-6400XT Portable Photosynthesis System; Li-Cor Biosciences, Lincoln NE, USA) connected to an individual leaf chamber 6400-02B LED light source, $2.5 \times 2.5 \mathrm{~cm}$. At the end of the $1 \mathrm{~h}$ of stresses or, in the case of WS, when $\Psi_{\mathrm{w}}$ was $-0.9 \mathrm{MPa}$, dark adaptation for chlorophyll $a$ fluorescence was performed for $15 \mathrm{~min}$ and the following dark-adapted parameters were measured: ground state fluorescence $\left(F_{o}\right)$, maximal fluorescence $\left(F_{m}\right)$, variable fluorescence $\left(F_{v}=F_{m}-F_{o}\right)$ and maximum quantum yield of the PSII system $\left(F_{v} / F_{m}=\left(F_{m}-\right.\right.$ $\left.\left.F_{o}\right) / F_{m}\right)$. The light-adapted measurements performed were the following: $\mathrm{qP}$, the light energy used in photosynthesis; $\mathrm{qN}$, the light energy not used in photosynthesis; NPQ $\left(F_{m} / F_{m}^{\prime}-1\right)$, an estimate of the light energy not used in photosynthesis, acting as an indicator of photoprotective processes through the dissi- 
pation of energy as heat (Ruban et al. 2012); $F_{v}{ }_{v} / F_{m}^{\prime}$, the maximum quantum efficiency of PSII in light-adapted leaves; and q, the operating quantum efficiency of PSII photochemistry. Chlorophyll $a$ fluorescence was measured using a Pulse Amplitude Modulation Fluorometer (mini-PAM, Photosynthesis Yield Analyzer; Walz, Effeltrich, Germany), with a saturation pulse intensity extending up to $18,000 \mu \mathrm{mol} \cdot$ photons $\cdot \mathrm{m}^{-2} \cdot \mathrm{s}^{-1}$ and actinic light corresponding to the photosynthetically active radiation (PAR).

Light curves were performed at ambient $\mathrm{CO}_{2}$ (ca. $350 \mu \mathrm{mol} \cdot \mathrm{mol}^{-1} \mathrm{CO}_{2}$ ) and different irradiances (I) measured were recorded every $380 \mathrm{~s}$ or before, if the photosynthesis rate had already stabilised, at each irradiance. Light intensities rose step-wise from 0 to $1750 \mu \mathrm{mol} \cdot \mathrm{m}^{-2} \cdot \mathrm{s}^{-1}$. Stomatal conductance $(g s)$ was measured at the same light intensities used for the photosynthesis curves and the value presented in Fig. 4 is that measured at the light intensity of growth (gs300). Dark respiration (Rd) was the intercept of the $A / I$ curve with the $y$-axis, the light compensation point (LCP) was the light intensity at which the release and consumption of oxygen were equal (intercept with the $x$-axis), and maximum photosynthesis rate $\left(A_{\max }\right)$ was given as the asymptotic $A$ value as irradiance tends to infinity. Using the previously estimated parameters, the further analysis of $A$ /I curves allowed the determination of $A_{\max }$ and Rd, using SPSS 17.0 software (SPSS, Chicago, IL, USA). Intrinsic water use efficiency (Wg) was also calculated by dividing $A$ by $g s$, both measured at $1750 \mu \mathrm{mol} \cdot$ quanta $\cdot \mathrm{m}^{-2} \cdot \mathrm{s}^{-1}$.

\section{Antioxidative metabolite quantification}

Reduced and oxidised glutathione and ascorbate concentrations were determined in leaves collected at the end of each stress treatment. Leaf material $(0.5 \mathrm{~g})$ was frozen in liquid $\mathrm{N}_{2}$. Each sample was homogenised in the presence of liquid $\mathrm{N}_{2}$ in $5 \mathrm{ml}$ ice-cold 6\% meta-phosphoric acid ( $\mathrm{pH} 2.8$ ) containing $1 \mathrm{mM}$ EDTA. Homogenates were centrifuged at 27,000 $\mathrm{g}$ for $15 \mathrm{~min}$ at $4{ }^{\circ} \mathrm{C}$ and the resulting acid extract was stored at $-80^{\circ} \mathrm{C}$.

Reduced (GSH) and oxidised (GSSG) glutathione were analysed colorimetrically by the 2-vinylpiridine method described in Anderson et al. (1995). GSH and GSSG concentrations were expressed in $\mu \mathrm{mol} \cdot \mathrm{g}^{-1} \mathrm{DW}$. Percentage reduction corresponds to the percentage of total glutathione pool present as GSH and is defined as $\mathrm{GSH} /(\mathrm{GSH}+\mathrm{GSSG}) \times 100$. AsA and dehydroascorbic (DAsA) acids were assayed using a method adapted from Okamura (1980) by Carvalho et al. (2015a). The concentration of DAsA was calculated by subtracting the AsA concentration measured from the total ascorbate determined. Standard curves of AsA in the range of $10-60 \mu \mathrm{M}$ were prepared in 5\% metaphosphoric acid. AsA and DAsA concentrations were expressed in $\mu \mathrm{mol} \cdot \mathrm{g}^{-1} \mathrm{DW}$.

\section{Abscisic acid quantification}

Abscisic acid (ABA) concentration was determined in leaves collected at the end of each stress treatment. The extracts were obtained as described in Vilela et al. (2007), and the quantification of $\mathrm{ABA}$ was performed through immunoassay by indirect enzyme-linked immunosorbent assay (ELISA) with monoclonal antibodies, using a commercial kit (Olchemim Enzyme Immunoassay, Olomouc, Czech Republic) according to the manufacturer's recommendations.

\section{Statistical analysis}

Six biological replicates were used for all treatments and quantifications. Two-way ANOva was used to study the effects of the stress treatments on the different physiological parameters and contents of $\mathrm{H}_{2} \mathrm{O}_{2}$, pigments, $\mathrm{ABA}, \mathrm{GSH}$ and AsA and their respective redox status in the two varieties studied. When the $P$-value of the ANOva was lower than 0.05 , treatments were compared with their respective controls and each treatment was compared in both varieties, through Tukey's multiple comparison tests and statistically significant differences were accepted for a $P$-value lower than 0.05 . These analyses were performed using SAS 9 for Windows (SAS Institute, Cary, NC, USA). In order to have an integrated view of the effects of the distinct abiotic stresses at the whole plant level and in order to relate the status of the photosynthetic apparatus with the response of the antioxidative machinery to stress in the different treatments, a principal components analysis (PCA) was performed using as variables some key parameters. As variables were measured in different scales and units they were standardised, and the respective correlation matrix was used to calculate the principal components. PCA was made in R (version 2.15.1; $\mathrm{R}$ Foundation for Statistical Computing, Vienna, Austria) using the packages FactoMineR (http://factominer.free.fr/) for multivariate analysis and ggplot2 (Wickham 2009) for the plotting and visualisation. Additionally, to complement the interpretation of the relationships among the studied variables, some descriptive analysis was performed through Pearson correlations between all pairs of parameters quantified in both varieties.

\section{RESULTS}

\section{Hydrogen peroxide $\left(\mathrm{H}_{2} \mathrm{O}_{2}\right)$}

Leaf $\mathrm{H}_{2} \mathrm{O}_{2}$ was quantified in Trincadeira (TR) and Touriga Nacional (TN) in all stress treatments (Fig. 2). In $\mathrm{TN}_{2} \mathrm{O}_{2}$ content did not change under WS but decreased after LS and $\mathrm{HS}$ and increased significantly after LSHS. In TR $\mathrm{H}_{2} \mathrm{O}_{2}$ content decreased only after WS.

\section{Chlorophyll fluorescence and photosynthetic parameters}

Photosynthetic light response curves for TN and TR are presented in Fig. 3. No significant changes were observed in TN when LS was compared to the control; there was a decrease of ca. $20 \%$ in LSHS, while HS, WS and WSHS were responsible for a significant $50 \%$ inhibition of the light response curves. The triple stress (WSLSHS) and WSLS imposed the most significant reduction of the photosynthesis response curves, with rates not exceeding $1 \mu \mathrm{mol} \cdot \mathrm{CO}_{2} \cdot \mathrm{m}^{-2} \cdot \mathrm{s}^{-1}$. In TR, the control was $20 \%$ higher than in TN (significant for $P<0.05$ ) and all the stress treatments caused significant reductions in the curves, $\mathrm{ca}$. $40 \%$ reduction in HS, LS and LSHS, $80 \%$ in WS and WSLS and WSHS and the triple stress had rates not exceeding $1 \mu \mathrm{mol} \cdot \mathrm{CO}_{2} \cdot \mathrm{m}^{-2} \cdot \mathrm{s}^{-1}$. In summary, for both varieties the WSincluding treatments significantly impaired photosynthetic capacity and the triple stress combination almost brought $\mathrm{CO}_{2}$ fixation to a halt.

Stomatal conductance $(g s)$ measured at $300 \mu \mathrm{mol}$. quanta $\cdot \mathrm{m}^{-2} \cdot \mathrm{s}^{-1}$, quantum yield of photosynthesis (q), light 


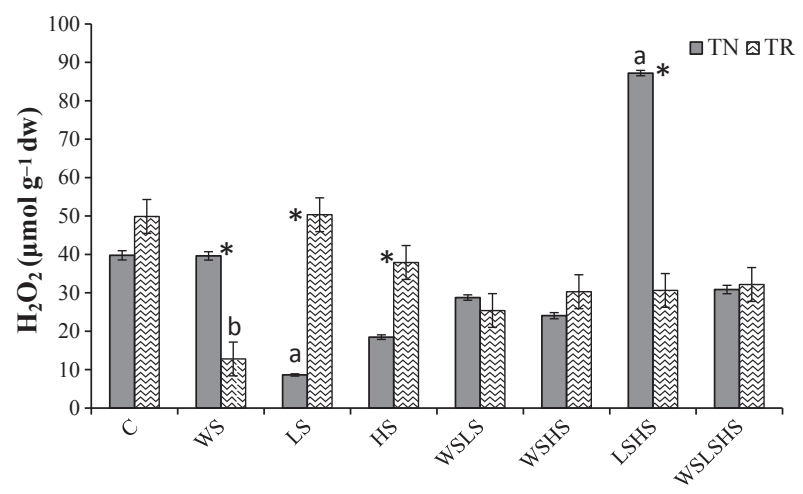

Fig. 2. Hydrogen peroxide quantification in leaves of Touriga Nacional (TN) and Trincadeira (TR) subjected to individual and combined stresses, as indicated in Fig. 1. Each value expressed in $\mu \mathrm{mol} \cdot \mathrm{g}^{-1}$ fresh weight is the mean of five independent samples measured in triplicate $(n=5)$. Statistically significant differences after Tukey's multiple comparison tests for $P<0.05$ are the following: *significant difference between TN and TR; ${ }^{a}$ significant difference

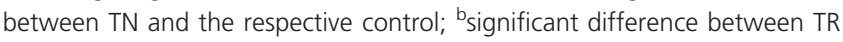
and the respective control.

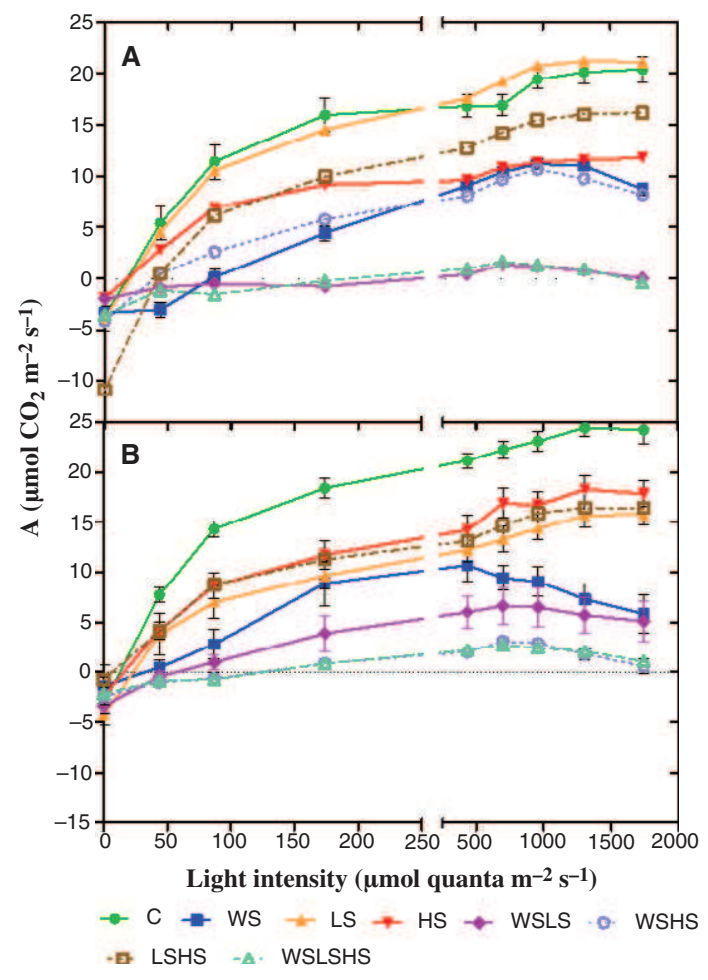

Fig. 3. Photosynthetic light response curves, measured in two grapevine varieties, Touriga Nacional (TN) (A) and Trincadeira (TR) (B). Plants were subjected to individual and combined stresses, as indicated in Fig. 1. Each curve is the mean of six independent curves $(n=6)$. Measurements were performed at increasing light intensity $\left(0-1750 \mu \mathrm{mol} \cdot\right.$ quanta $\left.\cdot \mathrm{m}^{-2} \cdot \mathrm{s}^{-1}\right)$ with a Li-Cor LI-6400. In all curves, means and error bars are shown for all light points, except when the error value is smaller than the symbol.

compensation point (LCP), dark respiration (Rd), intrinsic water use efficiency (Wg) and chlorophyll florescence parameters in the two grapevine varieties in control and stress-treated plants are shown in Fig. 4. gs significantly increased with the LS treatment in $\mathrm{TN}$ (275\% increase from the control), while the
WS-involved stresses led to significant decreases of $g s$ especially in TR (Fig. 4A). It is noteworthy that $g s$ curves were performed together with the light response curves and the values within each curve were strikingly similar (data not shown). Only the water-involved stresses affected LCP significantly in both varieties (Fig. 4B), the most significant increase occurring in the triple stress in TN. In TN Rd showed a slight tendency to decrease in response to WS (Fig. 4C), while TR registered significant decreases after LSHS and the triple stress. In TR Wg increased with HS and the double combinations of WS, while in TN the only significant increase occurred in WSHS (Fig. 4D). LS and the triple stress showed the lowest values in both varieties (not exceeding 20\% control values).

Chlorophyll fluorescence parameters reflecting the maximum efficiency of PSII photochemistry in dark- and in lightadapted leaves (respectively, $F_{v} / F_{m}$ and $F_{v}{ }_{v} / F_{m}{ }_{m}$ ) were affected by stress in a similar pattern in both varieties, suffering significant decreases, especially in TN for WSLS (Fig. 4E and F). $\mathrm{q}_{\mathrm{P}}$, which provides an estimate of the light energy used in photosynthesis, decreased significantly in TN after WS and LS and increased in TR under LS and LSHS (Fig. 4G). NPQ (nonphotochemical quenching, $F_{m} / F_{m}^{\prime}-1$ ) gives an estimate of the light energy not used in photosynthesis and functions as an indicator of photoprotective processes through the dissipation of energy as heat (Ruban et al. 2012), providing similar information to $\mathrm{q}_{\mathrm{N}}$ (also non-photochemical quenching, $F_{m}{ }_{m}-F v$ / $\left.F_{m}{ }_{m}\right)$. Both parameters increased significantly in TN under HS, and all stress combinations involving $\mathrm{HS}$ (Fig. $4 \mathrm{H}$ and I), and $\mathrm{q}_{\mathrm{N}}$ also increased significantly in TR under HS (Fig. 4I). The operating quantum efficiency of PSII photochemistry (q) decreased significantly under WS, HS, WSHS, WSLS and the triple stress in both varieties, and in TR it was significantly higher than in TN under C, WS and WSLS (Fig. 4J).

\section{Antioxidative metabolites, pigments and abscisic acid content}

Control levels of total ascorbate were lower in TR than in TN, as previously described (Carvalho et al. 2015a; Fig. 5A). Ascorbate values decreased in both varieties after all the stresses except TN-WS and TN-LSHS. The reduced pool increased under WS in TR and was lowest after WSLS in TN (Fig. 6A), In TN total glutathione levels increased significantly with WS, LSHS and the triple stress, while in the other stress treatments it was only the oxidised fraction that increased (Fig. 5B), leading to significant decreases of the reduced glutathione pool (Fig. 6B).

Chlorophyll quantity decreased in TN under the various stresses, with the exception of WSLS, similar to the control and the triple stress, which had higher levels of chlorophylls than the control (Fig. 5C) but with no changes in the chla/b ratio (Fig. 6C). Conversely, in LSHS, the total chlorophyll content was unchanged but the chla/b ratio increased significantly. In TR, chlorophylls had the opposite tendency, increasing slightly or significantly with stress (Fig. 5C) but with a tendency for higher chl $b$ values than the control, reflected in lower chla/b ratios (Fig. 6C). Carotenoid content increased significantly in TN subjected to the triple stress and decreased significantly in WSHS (Fig. 5D). In TR carotenoid content was quite constant within the various stress treatments (Fig. 5D). Following the same tendency as carotenoids in TN, anthocyanins were significantly higher in WSLSHS (Fig. 5E). 


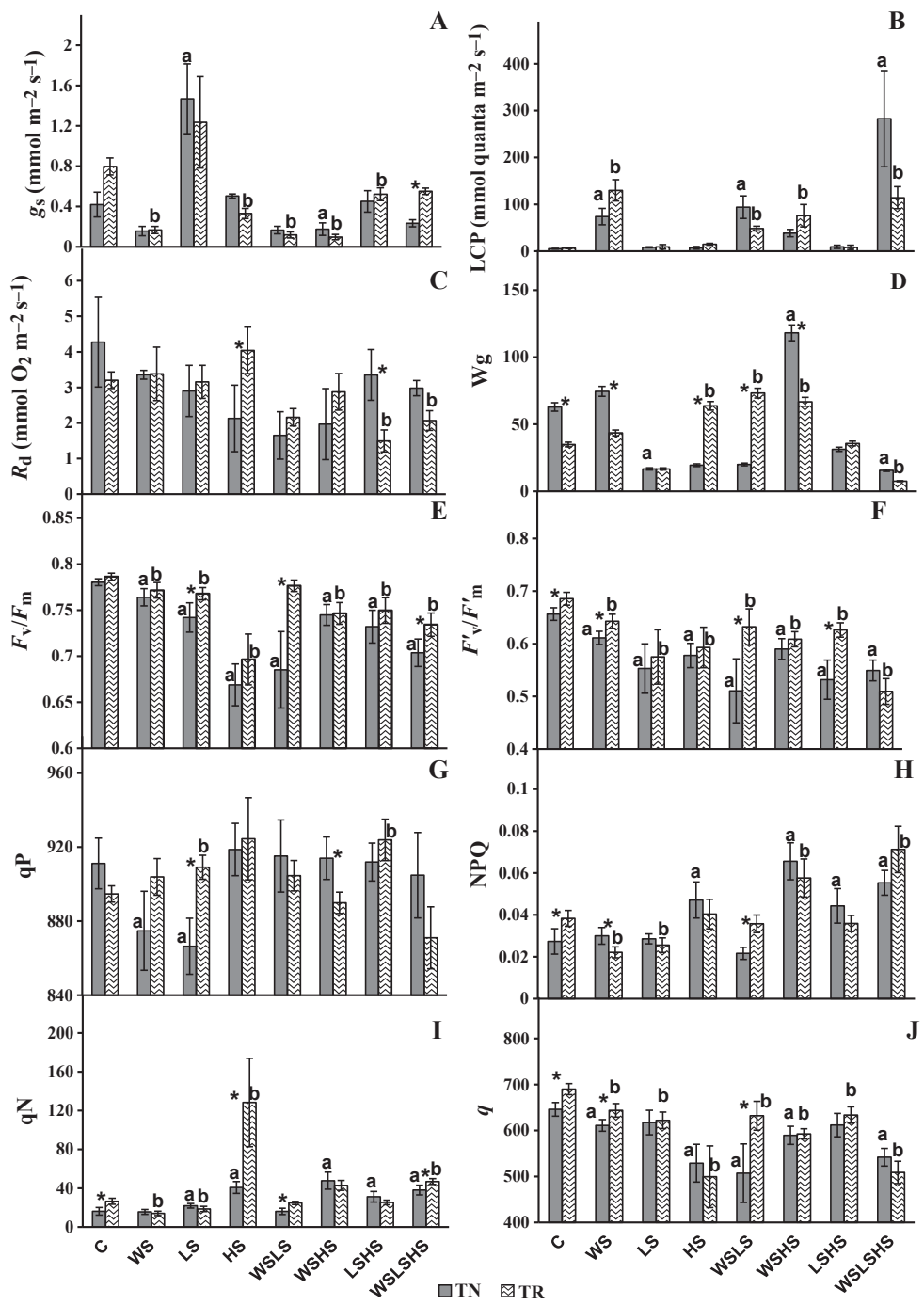

Fig. 4. Photosynthetic parameters measured in two grapevine varieties, Touriga Nacional (TN) and Trincadeira (TR), including measurements performed with a Li-Cor LI-6400, A to D, and those from chlorophyll fluorescence measurements, E to J. Plants subjected to individual and combined stresses, as indicated in Fig. 1. All values are mean of six independent samples $(n=6)$. gs $(\mathrm{A})$ is stomatal conductance at

$300 \mu \mathrm{mol} \cdot$ quanta $\cdot \mathrm{m}^{-2} \cdot \mathrm{s}^{-1}$, LCP (B) represents light compensation point, $\mathrm{Rd}(C)$ is dark respiration and $\mathrm{Wg}(\mathrm{D})$ is intrinsic water use efficiency, $F_{v} / F_{m}(E)$ represents the maximum efficiency of PSII photochemistry in darkadapted leaves, $q P(F)$ corresponds to light energy used in photosynthesis, $q N(\mathrm{G})$ corresponds to light energy not used in photosynthesis, NPQ $\left(F_{m} / F_{m}^{\prime}-1\right)(H)$ is an estimate of light energy not used in photosynthesis and functions as an indicator of photoprotective processes through the dissipation of energy as heat (DemmigAdams \& Adams 1992), $F^{\prime}{ }_{v} / F_{m}^{\prime}(I)$ corresponds to maximum quantum efficiency of PSII in light-adapted leaves, $q(\mathrm{~J})$ equates to operating quantum efficiency of PSII photochemistry. Values are accompanied by the respective SE. Statistically significant differences after Tukey's multiple comparison tests for $P<0.05$ are: *significant difference between TN and TR within a stress treatment; ${ }^{a}$ significant difference between TN and the respective control; bsignificant difference between TR and the respective control.
Abscisic acid (ABA) concentration in TN showed a tendency to significantly lower values after the combined stresses (except WSLS), while HS gave rise to significantly higher values than the respective control and TR. In TR, conversely to only LS, LSHS had the most significantly high ABA concentration (Fig. 5F).

\section{Integration of photosynthetic parameters with response of the} antioxidative machinery

In order to obtain an integrated view of the effects of the distinct abiotic stresses at the whole plant level with the grape varieties studied, a PCA of the data was performed, using as variables some of the key parameters that characterise the status of the photosynthetic apparatus in order to relate them to the response of the antioxidative machinery to stress in the different treatments. The biplots obtained relate LCP, $A_{\max }, \mathrm{GSH}$ and car (Fig. 7A and E); Chltot, GSSG, AsA and NPQ (Fig. 7B and $\mathrm{F}$ ); $\mathrm{q}_{\mathrm{P}}, \mathrm{LCP}, \mathrm{q}$ and total glutathione (Fig. $7 \mathrm{C}$ and $\mathrm{G}$ ) and \% GSH, $A_{\max }, \mathrm{H}_{2} \mathrm{O}_{2}$ and Chltot (Fig. 7D and $\mathrm{H}$ ) in TN and in TR. In all the biplots the existing variability is largely explained by the two-first principal components, with between $60 \%$ (Fig. 7A) and $80 \%$ (Fig. 7C) of the total variability, confirming that most of the tendencies observed in the above-mentioned results are reasonably reproduced and summarised. In TN LCP is negatively correlated with $A_{\max }$ along PCl (Fig. 7A), while in TR this correlation is less evident and LCP is negatively correlated with car along PC1 (Fig. 7E). AsA and GSSG are positively correlated with each other along $\mathrm{PCl}$ and are unrelated to Chltot in both varieties, although Chltot changes from the positive quadrant of PC2 in TN to the negative in TR (Fig. 7B and F). LCP and $\mathrm{q}_{\mathrm{P}}$ are negatively related with each other along $\mathrm{PC} 1$ in TN, while in TR there is a strong negative correlation of LCP with q, accounting for most of the data variance (Fig. 7C and $\mathrm{G}$ ). $A_{\max }$ and $\% \mathrm{GSH}$ are positively correlated in TR, while their relation is negative in $\mathrm{TN}$, and $\mathrm{H}_{2} \mathrm{O}_{2}$ has no significant effect over either parameter in both grape varieties (Fig. 7D and $\mathrm{H}$ ). Through this analysis it was possible to validate and support some results already found in the previous figures, such as that the triple stress gave lower values of $A_{\max }$ and higher values of LCP, especially in TN.

\section{DISCUSSION}

The aim of this work was to compare the effects of individual and combined stresses in controlled conditions, duplicating 

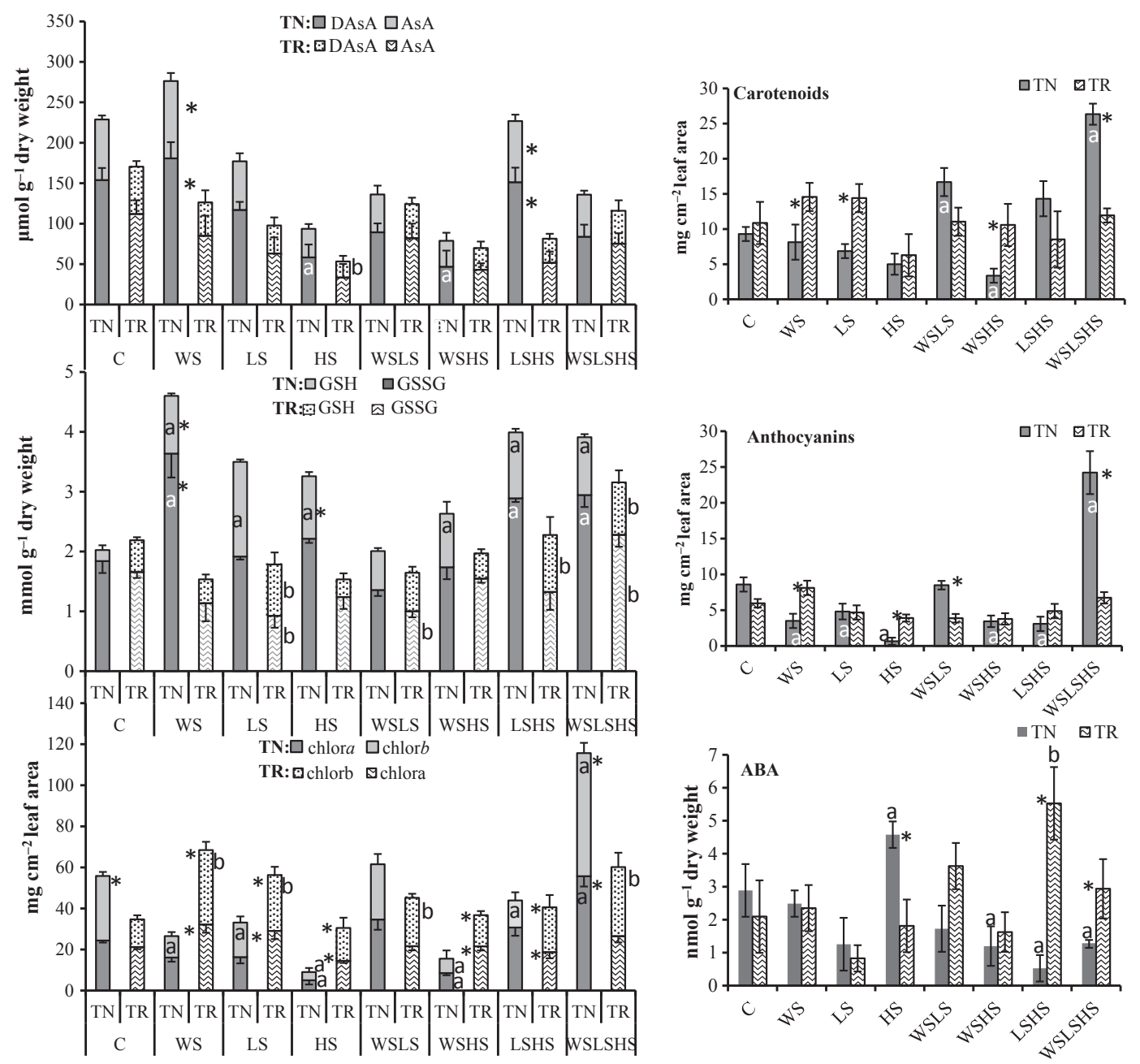

Fig. 5. Reduced (ASA) and oxidised (DAsA) ascorbate (A) and reduced (GSH) and oxidised (GSSG) glutathione (B) concentration, chlorophyll a and $b$ concentration (C), carotenoid concentration (D), anthocyanin concentration (E) and ABA content (F) in leaves of Touriga Nacional (TN) and Trincadeira (TR). Plants were subjected to individual and combined stresses as indicated in Fig. 1. Each value is the mean of five independent samples measured in triplicate ( $n=5$ ). Statistically significant differences after Tukey's multiple comparison tests for $P<0.05$ are: *significant difference between TN and TR; ${ }^{a}$ significant difference between TN and the respective control; ${ }^{b}$ significant difference between TR and the respective control.

those most often found in the Mediterranean environment, on the physiology of the grapevine varieties Touriga Nacional (TN) and Trincadeira (TR). The conditions are drought, high light and heat, individually or in combination. The cautious use of the obtained information could contribute to better manage grapevines under field conditions. The stresses imposed in the current study altered most of the leaf gas exchange and chlorophyll fluorescence parameters, as well as the concentrations of ABA and antioxidative metabolites. Most of these traits have been shown to be correlated with fitness across many different studies and species (Ungerer et al. 2002; Geber \& Griffen 2003; Johnson et al. 2009), suggesting that the imposed conditions duplicate the agroecological stress.

In the current study, WS was the strongest of the three individual stresses applied, considering the photosynthetic adjustments undertaken by plants of both grape varieties (Figs 3, 4). Photosynthesis rates decreased significantly from the controls in all conditions but TN-LS. TR retained higher control values than TN but similar values under stress, which did not occur in the field under Mediterranean summer conditions, with TN showing higher apparent photosynthesis rates than TR (Costa et al. 2012). When, in addition to WS, plants are subjected to other environmental stresses such as high light and/or high temperature, photoinhibition is likely to occur. In fact, under conditions that impair $\mathrm{CO}_{2}$ fixation, such as WS, the rate of reducing power use by the Calvin cycle is lower than the rate of its production, thus leading to the need for protection mechanisms against excess reducing power (Chaves et al. 2009). These photoprotective mechanisms compete with photochemistry for the absorbed energy, leading to a decrease in the quantum yield of PSII (Genty et al. 1989), as was the case for TN and TR plants under WS and in all its combinations (Fig. 4), even reaching extremely low values. Even the maximum efficiency of PSII photochemistry in dark-adapted leaves $\left(F_{v} / F_{m}\right)$ decreased significantly under all stresses, especially in TN (Fig. 4E), a response that had not occurred in the field under Mediterranean summer conditions (Costa et al. 2012). The regulated thermal dissipation in light-harvesting complexes (Demmig-Adams \& Adams 1992), as quantified by $\mathrm{q}_{\mathrm{N}}$ and NPQ, may assist in achieving photoprotection. In our case, however, 

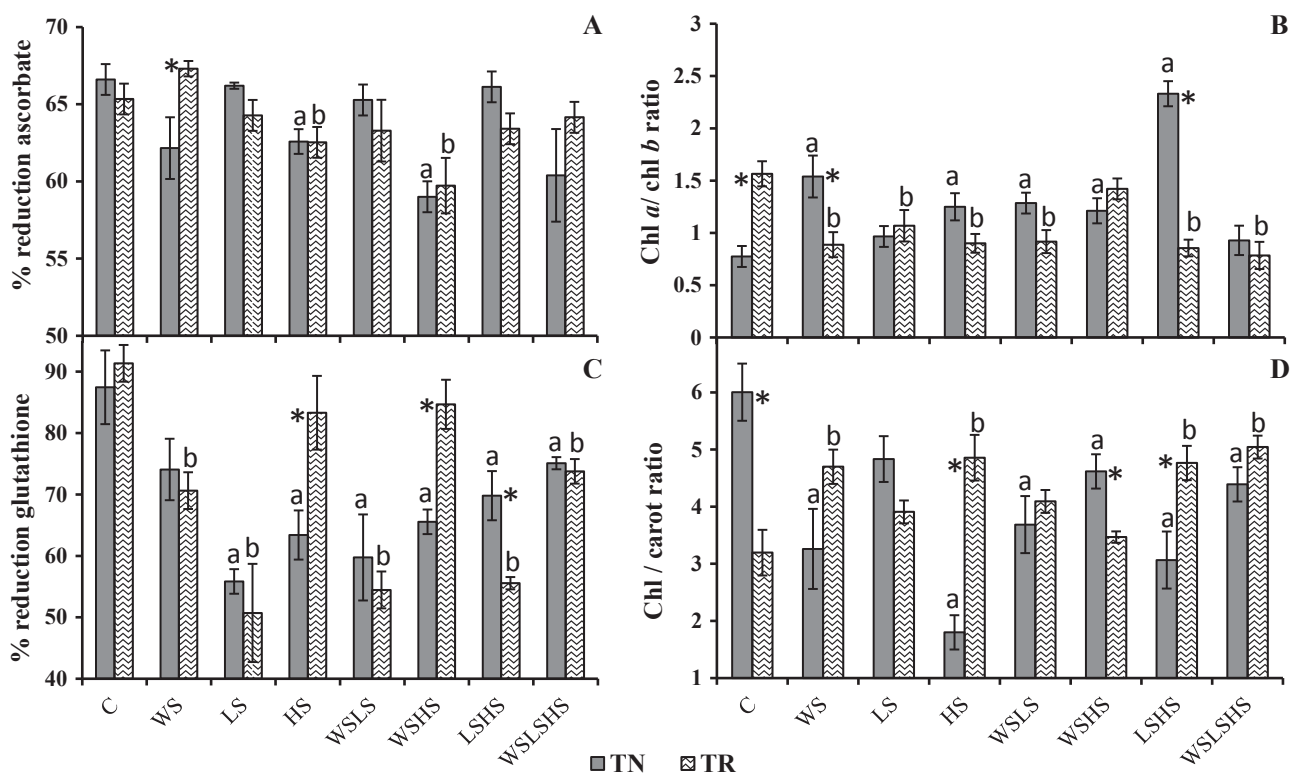

Fig. 6. Percentage (\%) reduction of ascorbate and of glutathione (A and B), total chlorophyll/carotenoid ratio (C) and chlorophyll a/chlorophyll $b$ ratio (D), in leaves of Touriga Nacional (TN) and Trincadeira (TR). Plants were subjected to individual and combined stresses as indicated in Fig. 1. Each value is the mean of five independent samples measured in triplicate $(n=5)$. Statistically significant differences after Tukey's multiple comparison tests for $P<0.05$ are: *significant difference between TN and TR; ${ }^{a}$ significant difference between TN and the respective control; ${ }^{b}$ significant difference between TR and the respective control.

this dissipation tended to be highest in HS and its combinations, while when heat was not present the values of these parameters did not exceed the control (Fig. $4 \mathrm{H}$ and I). In fact, the combination of drought and heat (WSHS) led to significantly high values of $\mathrm{Wg}$ (intrinsic water use efficiency), mostly due to the very low values of $g s$, especially in TR. In TN apparent photosynthesis was positively correlated with both gs300 (Table S1) and $g s 1750$ in all drought-involved stresses, a result that can indicate high rates of water use and water use efficiency (Edwards et al. 2011), and which is in accordance with measurements in the field, where TN retained higher $g s$ than Syrah, Aragonez, Cabernet Sauvignon and TR for equivalent $\Psi_{\mathrm{w}}$ (Chaves et al. 2010), corroborating the indication that TN shows an anisohydric type of response that is closer to the overall characterisation of the species.

As a ROS, $\mathrm{H}_{2} \mathrm{O}_{2}$ production increases upon stress but this molecule is also involved in signalling pathways set in motion to control various biological processes, namely the response to abiotic stress (Foyer \& Noctor 2005; Mullineaux et al. 2006). The Mehler reaction is the chief source of $\mathrm{H}_{2} \mathrm{O}_{2}$ in chloroplasts, and the rate of $\mathrm{O}_{2}$ photoreduction relies on environmental conditions (Slesak et al. 2007). In the current study, $\mathrm{H}_{2} \mathrm{O}_{2}$ did not change significantly in most of the stresses applied, despite the decreasing photosynthesis rates. In TN-LS, $\mathrm{H}_{2} \mathrm{O}_{2}$ decreased significantly while photosynthesis rates increased. In the other two conditions in which $\mathrm{H}_{2} \mathrm{O}_{2}$ decreased (TN-HS and TR-WS), photosynthesis rates also decreased, namely in TR-WS, where there was a significant negative correlation between $\mathrm{H}_{2} \mathrm{O}_{2}$ and quantum efficiency of photosynthesis (Table S1).

L-Ascorbic acid (AsA) and glutathione (GSH) are key antioxidants in the detoxification of ROS that eliminate $\mathrm{H}_{2} \mathrm{O}_{2}$ through the ascorbate-glutathione (asc-glut) cycle (for a review of their role in grapevine see Carvalho et al. 2015b). In control conditions TN had higher levels of total ascorbate than TR, as previously reported (Carvalho et al. 2015a), and slightly higher AsA percentage than TR. Upon the WSHS combination, redox percentage decreased in both varieties, indicating difficulty in maintaining the cellular redox state. The levels of glutathione and its redox state changed more significantly than those of AsA upon the various stresses applied. Total glutathione increased significantly in TN-WS and in WSLSHS in both varieties. In all stress situations, TN had higher total levels than TR, mostly due to an increase in GSSG (e.g. TN-LS). This indicates strong activation of the whole asc-glut cycle to help keep the ascorbate pool reduced (Carvalho et al. 2015b) and scavenge the $\mathrm{H}_{2} \mathrm{O}_{2}$ produced.

Pigments such as carotenoids protect the photosynthetic apparatus against photooxidative damage by quenching the triplet states of chlorophyll molecules (Koyama 1991) but also by direct scavenging of ROS (Edge et al. 1997). As mentioned before in a heat stress study, TR relies more on carotenoids than TN for the scavenging of ROS (Carvalho et al. 2015a). In fact, in TR carotenoids seem to play a more relevant role in ROS scavenging than the asc-glut cycle itself, as the negative correlations between pigments and GSSG indicate. As the cycle is impaired by the increase in GSSG, the AsA that becomes available from the cycle may be diverted into direct protection of carotenoid integrity, and thus carotenoids are able to assume a more prominent role.

Anthocyanins are involved in tolerance to a panoply of stresses, such as drought, UV-B, heavy metals, as well as in biotic stress resistance. Anthocyanic cell vacuoles absorb high-energy quanta, protecting chloroplasts from the photoinhibitory and photo-oxidative effects of high light, and prevent the catabolism of photolabile defence compounds (Gould 2004). Anthocyanins are also able to assuage photo-oxidative damage in leaves due to their ability to scavenge ROS (Gould 2004). In both TN and TR anthocyanins were not the most responsive pigments to stress, with the exception of TN-WSLSHS. 
Fig. 7. $P C A$ and biplots in Touriga Nacional (TN) (A-D) and in Trincadeira (TR) (E-H) with variables: $L C P, A_{\max }$, GSH and car (A, E); Chltot, GSSG, AsA and NPQ (F, B); $\mathrm{qP}, \mathrm{LCP}, \mathrm{q}$ and glut $(\mathrm{C}, \mathrm{G})$; and $\% \mathrm{GSH}, \mathrm{A}_{\max }, \mathrm{H}_{2} \mathrm{O}_{2}$ and Chltot $(D, H)$. Parameters are the following: car: carotenoids; Chltot: total chlorophyll; LCP: light compensation point; $A_{\max }$ : maximum rate of photosynthesis; \%GSH: percentage reduced glutathione; AsA: ascorbic acid; GSSG: oxidised glutathione; GSH: reduced glutathione; qP: photochemical quenching; q: quantum yield of photosynthesis; glut: total glutathione; NPQ: non-photochemical quenching, $\mathrm{H}_{2} \mathrm{O}_{2}$ : hydrogen peroxide

concentration. Analyses were performed with the individual data of all replicates after normalisation.

Conversely to TR, in TN the combined HS-including stresses led to a decrease in ABA content. When WS is combined with $\mathrm{HS}$, the response of ABA can shift from the expected response to WS. In several species (Bellis perennis, Cardamine pratensis, Commelina communis) stomata did not respond to ABA at normal growth temperatures, while typical ABA-induced stomatal closure was induced by heat, up to $30^{\circ} \mathrm{C}$ (Pospisilova \& Dodd 2005). In this work, heat did in fact lead to an increase of ABA concentration independently of drought (HS alone in TN and LSHS in TR). Stomatal conductance was high in LS, as expected (Mittler 2006), while ABA was low. In the combined stresses in TN, stomatal closure was independent of ABA. This behaviour may be similar to the mechanism described in Arabidopsis germinating seeds, in which protection from desicca-

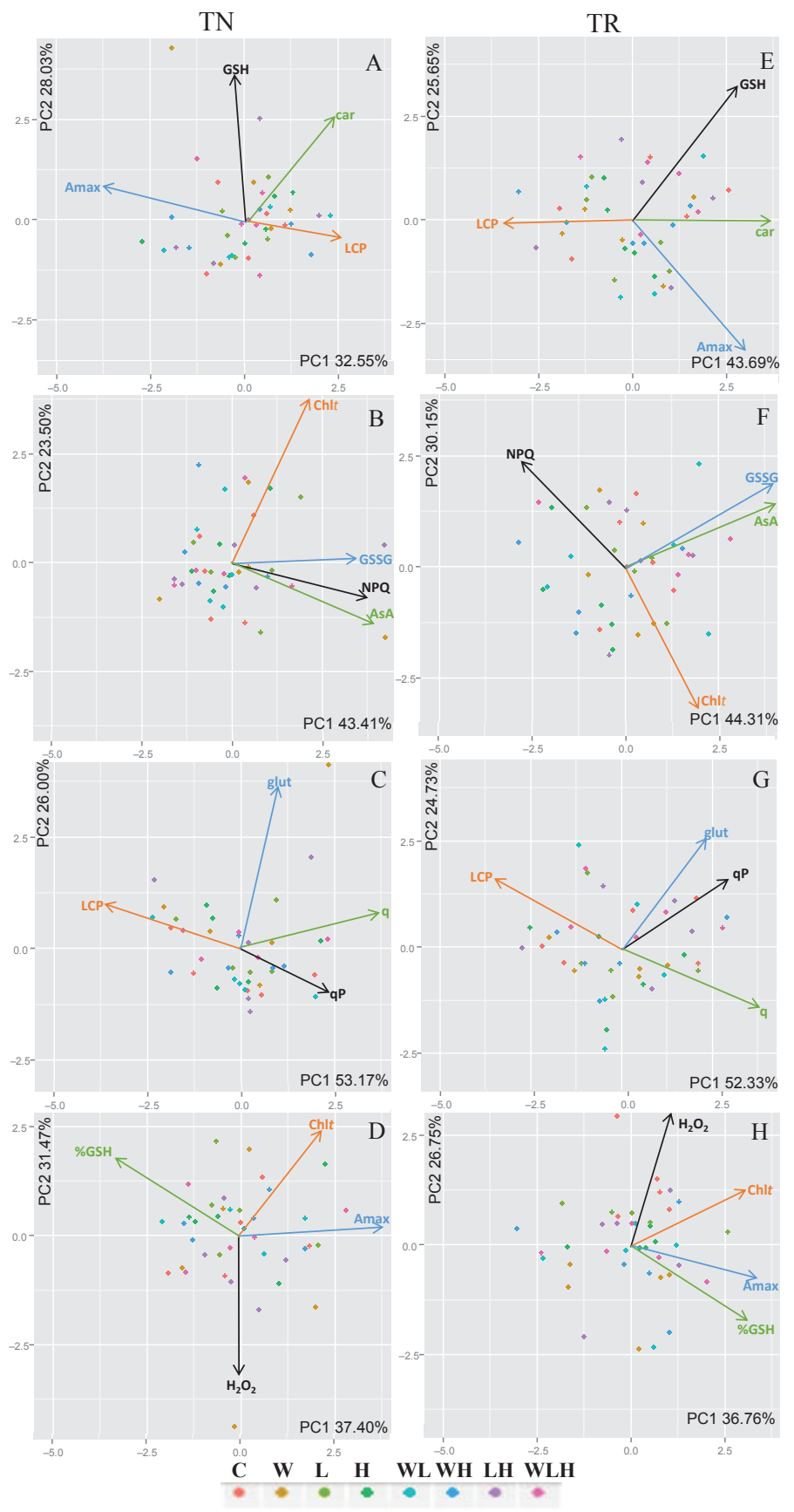

tion derived from ROS signalling instead of ABA (Chen et al. 2014). In TR, ABA content increased significantly with a combination of LS and HS, but not with WS, an atypical behaviour that can be explained by more rapid adaptation of this variety to the imposed WS. While ABA concentration in field-grown leaves of TN and TR (data not shown) was almost twofold higher than in leaves of plants grown under control conditions, the values measured in the latter $\left(1.0\right.$ to $\left.6.0 \mathrm{nmol} \cdot \mathrm{g}^{-1} \cdot \mathrm{DW}\right)$ were similar to values obtained in leaves of potted Sultana vines when irrigated (lowest values, $c a .1 .0 \mathrm{nmol} \cdot \mathrm{g}^{-1}$.DW) and without irrigation (highest values, ca. $4.0 \mathrm{nmol} \cdot \mathrm{g}^{-1} \cdot \mathrm{DW}$, with $\Psi$ reaching -1.0 MPa; Stoll et al. 2000). However, in field-grown $\mathrm{TN}$ and TR drought affected ABA concentration in different ways: when $\Psi$ was $<-0.7 \mathrm{MPa}$ TN suffered a significant 
increase in ABA, the typical ABA textbook response to drought, as also reported for the field-grown red variety Castelão and the white variety Moscatel (syn. Muscat of Alexandria; Rodrigues et al. 2008), while TR recorded a significant ABA decrease. This may indicate that other chemical signals, e.g. cytokinins, ethylene, alterations in ion content of xylem sap or changes in apoplastic pH in leaves (Wilkinson \& Davies 2002; Schachtman \& Goodger 2008), and not just ABA might be involved in that regulation. The changes in size and redox state of the GSH pool at the cellular level are also very important for the response to abiotic stress (Meyer 2008), as the results obtained in these two varieties indicate. In TN-WS there was a significant increase in the GSH pool, which can increase tolerance to drought (Chen et al. 2012). In TN-WS these changes do not seem to have been mediated by ABA (Wilkinson \& Davies 2002; Rodrigues et al. 2008), as ABA concentrations remained mostly unchanged and the significant increase in total glutathione, when compared to the control, points to de novo synthesis.

Plant growth and development is ultimately regulated by overall net carbon gain, the balance between photosynthesis and respiration. Indeed, it is estimated that leaf respiration allows well-watered plants to lose $30 \%$ to $70 \%$ of the $\mathrm{CO}_{2}$ fixed per day in photosynthesis (Atkin \& Macherel 2009). The impact of water deficits on dark respiration is not yet fully understood and there are many opposing reports in the available literature regarding the rates of this process (Gimeno et al. 2010). The decrease of $\mathrm{Rd}$ in the triple stress in TR can be explained by lower availability of the substrate to the mitochondria under conditions of low photosynthesis (Flexas et al. 2006). Usually, there is a positive correlation between the increase in irradiance and that of Rd. The pattern of response of Rd in TR, absence of change in WS and HS, although less frequent, has been reported in several species, mostly evergreen perennials (Gimeno et al. 2010).

\section{CONCLUSIONS}

By comparing the responses of two grapevine varieties to different stress treatments, common and distinct stress response features emerged, namely regarding the response to drought.
Each genotype shows a specific response to water deficit, heat and light, suggesting that they could adapt to the different experimental conditions. In TN photosynthesis was unaffected under LS, and this variety managed to keep stomata open, which is beneficial not only for photosynthesis but also for heat dissipation via evaporative cooling (high values of $g s$ ), indicating adaptation of TN to warmer conditions, as proposed by Costa et al. (2012) for field-grown plants. However, this is not the case in WS, because photosynthesis was severely impaired when WS and LS were combined or upon the combination of all three stresses, indicating that TN behaves as 'tolerant' to abiotic stress as it does not involve lack of water. TR, on the other hand, had reduced photosynthetic capacity under individual stresses, WS increased respiration and HS reduced significantly the channelling of captured energy towards photosynthesis. This indicates that TR behaves as 'sensitive' to abiotic stress. If the above results can be extrapolated to grapevine culture in the field, the use of TR in warm regions should be carefully considered, while TN will easily tolerate growth in such regions, as long as irrigation is provided.

\section{ACKNOWLEDGEMENTS}

The authors wish to thank Dr Patrícia Vidigal for the artwork of Fig. 1. The research was funded by Fundação para a Ciência e Tecnologia (FCT) through project PTDC/AGR-GPL/099624/ 2008, which included a research grant to JLC, CBAA Funding (PestOE/AGR/UI0240/2011) and SFRH/BPD/85767/2012 to LC. This work also benefited from networking activities within the European project KBBE InnoVine (ref. 311775) and the European COST Action FA1106 'QualityFruit'.

\section{SUPPORTING INFORMATION}

Additional Supporting Information may be found in the online version of this article:

Table S1. Pearson correlations of all parameters quantified in Touriga Nacional (TN) and Tricadeira (TR) in all treatments.

\section{REFERENCES}

Anderson M.D., Prasad T.K., Stewart C.R. (1995) Changes in isozyme profiles of catalase, peroxidase and glutathione reductase during acclimation to chilling in mesocotyls of maize seedlings. Plant Physiology, 109, 1247-1257.

Atkin O.K., Macherel D. (2009) The crucial role of plant mitochondria in orchestrating drought tolerance. Annals of Botany, 103, 581-597.

Carvalho L.C., Coito J.L., Colaço S., Sangiogo M., Amâncio S. (2015a) Heat stress in grapevine: the pros and cons of acclimation. Plant, Cell and Environment, 38, 777-789.

Carvalho L.C., Vidigal P., Amâncio S. (2015b) Oxidative stress homeostasis in grapevine (Vitis vinifera L.). Frontiers in Environmental Science, 3, 20.

Castellarin S.D., Matthews M., Di Gaspero G., Gambetta G. (2007) Water deficits accelerate ripening and induce changes in gene expression regulating flavonoid biosynthesis in grape berries. Planta, 227, $101-112$
Chaves M.M. (2002) How plants cope with water stress in the field? Photosynthesis and growth. Annals of Botany, 89, 907-916.

Chaves M.M., Maroco J.P., Pereira J.S. (2003) Understanding plant responses to drought - from genes to the whole plant. Functional Plant Biology, 30, 239264

Chaves M.M., Flexas J., Pinheiro C. (2009) Photosynthesis under drought and salt stress: regulation mechanisms from whole plant to cell. Annals of Botany, 103, 551-560.

Chaves M.M., Zarrouk O., Francisco R., Costa J.M., Santos T., Regalado A.P., Rodrigues M.L., Lopes C.M. (2010) Grapevine under deficit irrigation: hints from physiological and molecular data. Annals of Botany, 105, 661-676.

Chen J.H., Jiang H.W., Hsieh E.J., Chen H.Y., Chien C.T., Hsieh H.L., Lin T.P. (2012) Drought and salt stress tolerance of an Arabidopsis glutathione Stransferase U17 knockout mutant are attributed to the combined effect of glutathione and abscisic acid. Plant Physiology, 158, 340-351.
Chen C., Letnik I., Hacham Y., Dobrev P., Ben-Daniel B.-H., Vanková R., Amir R., Miller G. (2014) ASCORBATE PEROXIDASE6 protects Arabidopsis desiccating and germinating seeds from stress and mediates cross talk between reactive oxygen species, abscisic acid, and auxin. Plant Physiology, 166, 370383

Costa J.M., Ortuño M.F., Lopes C.M., Chaves M.M. (2012) Grapevine varieties exhibiting differences in stomatal response to water deficit. Functional Plant Biology, 39, 179-189.

Creissen G., Firmin J., Fryer M., Kular B., Leyland N., Reynolds H., Pastori G., Wellburn F., Baker N., Wellburn A., Mulineaux P. (1999) Elevated glutathione biosynthetic capacity in the chloroplasts of transgenic tobacco plants paradoxically causes increased oxidative stress. The Plant Cell, 11, 1277-1291.

Deluc L.G., Quilici D.R., Decendit A., Grimplet J., Wheatley M.D., Schlauch K., Mérillon J.-M., Cushman J.C., Cramer G.R. (2009) Water deficit alters differentially metabolic pathways affecting important flavor and quality traits in grape berries of 
Cabernet Sauvignon and Chardonnay. BMC Genomics, 10, 212.

Demmig-Adams B., Adams W.W. III (1992) Photoprotection and other responses of plants to high light stress. Annual Review of Plant Physiology and Plant Molecular Biology, 43, 599-626.

Edge R., Mcgarvey D.J., Truscott T.G. (1997) The carotenoids as anti-oxidants - a review. Journal of Photochemistry and Photobiology, 41, 189-200.

Edwards C.E., Ewers B.E., Williams D.G., Xie Q., Lou P., Xu X., McClung C.R., Weinig C. (2011) The genetic architecture of ecophysiological and circadian traits in Brassica rapa. Genetics, 189, 375-390.

Flexas J., Bota J., Galmés J., Medrano H., Ribas-Carbo M. (2006) Keeping a positive carbon balance under adverse conditions: responses of photosynthesis and respiration to water stress. Physiologia Plantarum, 127, 343-352.

Foyer C.H., Noctor G. (2005) Redox homeostasis and antioxidant signaling: a metabolic interface between stress perception and physiological responses. The Plant Cell, 17, 1866-1875.

Geber M.A., Griffen L.R. (2003) Inheritance and natural selection on functional traits. International Journal of Plant Sciences, 164, S21-S42.

Genty B., Briantais J.M., Baker N.R. (1989) The relationship between the quantum yield of photosynthetic electron-transport and quenching of chlorophyll fluorescence. Biochimica et Biophysica Acta, 990, 87-92.

Gimeno T., Sommerville K., Valladares F., Atkin O. (2010) Homeostasis of respiration under drought and its important consequences for foliar carbon balance in a drier climate: insights from two contrasting Acacia species. Functional Plant Biology, 37, 323-333.

Gould K.S. (2004) Nature's Swiss army knife: the diverse protective roles of anthocyanins in leaves. Journal of Biomedicine and Biotechnology, 2004, 314-320.

Ingram J., Bartels D. (1996) The molecular basis of dehydration tolerance in plants. Annual Review of Plant Physiology and Plant Molecular Biology, 47, 377-403.

Johnson M.T.J., Agrawal A., Maron J.L., Salminen J.-P. (2009) Heritability, covariation and natural selection on 24 traits of common evening primrose (Oenothera biennis) from a field experiment. Journal of Evolutionary Biology, 22, 1295-1307.

Kellos T., Tımar I., Szilagyi V., Szalai G., Galiba G., Kocsy G. (2008) Stress hormones and abiotic stresses have different effects on antioxidants in maize lines with different sensitivity. Plant Biology, 10, 563-572.

Knight H., Knight M.R. (2001) Abiotic stress signalling pathways: specificity and cross-talk. Trends in Plant Science, 6, 262-267.

Kocsy G., Szalai G., Galiba G. (2004) Effect of osmotic stress on glutathione and hydroxymethylglutathione accumulation in wheat. Journal of Plant Physiology, 161, 785-794.

Kotak S., Larkindale J., Lee U., von Koskull-Döring P., Vierling E., Scharf K.-D. (2007) Complexity of the heat stress response in plants. Current Opinion in Plant Biology, 10, 310-316.

Koyama Y. (1991) Structures and functions of carotenoids in photosynthetic systems. Journal of Photochemistry and Photobiology, 9, 265-280.
Kranner I., Beckett R.P., Wornik S., Zorn M., Pfeifhofer H.W. (2002) Revival of a resurrection plant correlates with its antioxidant status. The Plant Journal, 31, 13-24.

Kwak J.M., Nguyen V., Schroeder J.I. (2006) The role of reactive oxygen species in hormonal responses. Plant Physiology, 141, 323-329.

Meyer A.J. (2008) The integration of glutathione homeostasis and redox signaling. Journal of Plant Physiology, 165, 1390-1403.

Mishra Y., Jänkänpää H.J., Kiss A.Z., Funk C., Schröder W.P., Jansson S. (2012) Arabidopsis plants grown in the field and climate chambers significantly differ in leaf morphology and photosystem components. BMC Plant Biology, 12, 6 .

Mittler R. (2006) Abiotic stress, the field environment and stress combination. Trends in Plant Science, 11, 15-19.

Mittler R., Vanderauwera S., Gollery M., Van Breusegem F. (2004) Reactive oxygen gene network of plants. Trends in Plant Science, 9, 490-498.

Mittova V., Guy M., Tal M., Volokita M. (2004) Salinity up-regulates the antioxidative system in root mitochondria and peroxisomes of the wild salt-tolerant tomato species Lycopersicon pennellii. Journal of Experimental Botany, 55, 1105-1113.

Morison J.I.L., Morecroft M. (2006) Plant growth and climate change. Blackwell, Oxford, UK, p 213.

Mullineaux P.M., Karpinski S., Baker N.R. (2006) Spatial dependence for hydrogen peroxide-directed signaling in light-stressed plants. Plant Physiology, 141, 346-350.

Noctor G., Mhamdi A., Queval G., Foyer C.H. (2013) Regulating the redox gatekeeper: vacuolar sequestration puts glutathione disulfide in its place. Plant Physiology, 163, 665-671.

Okamura M. (1980) An improved method for determination of L-ascorbic acid and L-dehydroascorbic acid in blood plasma. Clinica Chimica Acta, 103, 259-268.

Pastori G.M., Foyer C.H. (2002) Common components, networks, and pathways of cross-tolerance to stress. the central role of "redox" and abscisic acidmediated controls. Plant Physiology, 129, 460-468.

Pospisilova J., Dodd I.C. (2005) Role of plant growth regulators in stomatal limitation to photosynthesis. In: Pessarakli M. (Ed), Handbook of photosynthesis, 2nd edn. Marcel Dekker, New York, NY, USA, pp 811-825.

Rhue R., Grogan C., Stockmeyer E., Evert H. (1978) Genetic control of aluminium tolerance in corn. Crop Science, 18, 1063-1067.

Richardson A.D., Duigan S.P., Berlyn G.P. (2002) An evaluation of noninvasive methods to estimate foliar chlorophyll content. New Phytologist, 153, 185-194.

Rizhsky L., Liang H., Mittler R. (2002) The combined effect of drought stress and heat shock on gene expression in tobacco. Plant Physiology, 130, 1143 1151.

Rodrigues M.L., Santos T.P., Rodrigues A.P., de Souza C.R., Lopes C.M., Maroco J.P., Pereira J.S., Chaves M.M. (2008) Hydraulic and chemical signalling in the regulation of stomatal conductance and plant water use in field grapevines growing under deficit irrigation. Functional Plant Biology, 35, 565-579.
Ruban A.V., Johnson M.P., Duffy C.D.P. (2012) The photoprotective molecular switch in the photosystem II antenna. Biochimica et Biophysica Acta, 1817, 167-181.

Schachtman D.P., Goodger J.Q.D. (2008) Chemical root to shoot signaling under drought. Trends in Plant Science, 13, 281-287.

Seki M., Umezawa T., Urano K., Shinozaki K. (2007) Regulatory metabolic networks in drought stress responses. Current Opinion in Plant Biology, 10 296-302.

Sims D., Gamon J. (2002) Relationships between leaf pigment content and spectral reflectance across a wide range of species, leaf structures and developmental stages. Remote Sensing of Environment, 81, 337-354.

Slesak I., Libik M., Karpinska B., Karpinski S., Miszalski Z. (2007) The role of hydrogen peroxide in regulation of plant metabolism and cellular signalling in response to environmental stresses. Acta Biochimica Polonica, 54, 39-50.

Stoll M., Loveys B., Dry P. (2000) Hormonal changes induced by partial root zone drying of irrigated grapevine. Journal of Experimental Botany, 51, 16271634.

Szalai G., Kellős T., Galiba G., Kocsy G. (2009) Glutathione as an antioxidant and regulatory molecule in plants under abiotic stress conditions. Journal of Plant Growth Regulation, 28, 66-80.

Ungerer M.C., Halldorsdottir S.S., Modliszewski J.L., Mackay T.F.C., Purugganan M.D. (2002) Quantitative trait loci for inflorescence development in Arabidopsis thaliana. Genetics, 160, 11331151.

Verslues P.E., Agarwal M., Katiyar-Agarwal S., Zhu J., Zhu J.-K. (2006) Methods and concepts in quantifying resistance to drought, salt and freezing, abiotic stresses that affect plant water status. The Plant Journal, 45, 523-539.

Vilela B.J., Carvalho L.C., Ferreira J., Amâncio S. (2007) Gain of function of stomatal movements in rooting Vitis vinifera $\mathrm{L}$. plants: regulation by $\mathrm{H}_{2} \mathrm{O}_{2}$ is independent of $\mathrm{ABA}$ before the protruding of roots. Plant Cell Reports, 26, 2149-2157.

Vinocur B., Altman A. (2005) Recent advances in engineering plant tolerance to abiotic stress: achievements and limitations. Current Opinion in Biotechnology, 16, 123-132.

Wang W., Vinocur B., Altman A. (2003) Plant responses to drought, salinity and extreme temperatures: towards genetic engineering for stress tolerance. Planta, 218, 1-14.

Wickham H. (2009) ggplot2: Elegant graphics for data analysis. Springer Science+Business Media, Berlin, Germany, p 224.

Wilkinson S., Davies W.J. (2002) ABA-based chemical signalling: the co-ordination of responses to stress in plants. Plant, Cell and Environment, 25, 195-210.

Yang S.S., Cheung F., Lee J.J., Ha M., Wei N.E., Sze S.-H., Stelly D.M., Thaxton P., Triplett B. Town C.D., Chen Z.J. (2006) Accumulation of genome-specific transcripts, transcription factors and phytohormonal regulators during early stages of fiber cell development in allotetraploid cotton. The Plant Journal, 47, 761-775.

Zhu J.-K. (2002) Salt and drought stress signal transduction in plants. Annual Review of Plant Biology, 53, 247-273. 